\title{
Social Context of Solid Waste Disposal among Residents of Ibadan Metropolis, Nigeria
}

\author{
Temitope A. Ogunweide \\ Centre for Sustainable Development, University of Ibadan, Nigeria. \\ Email: snowgy2001@gmail.com
}

\begin{abstract}
Keywords: Sustainable Waste Management, Waste handling, Ibadan Metropolis, Landfill, Municipal Solid Waste
\end{abstract}

\begin{abstract}
The study sought to assess the social context of solid waste disposal pattern of residents in Ibadan metropolis, in order to assess the Solid waste disposal patterns of people in Ibadan metropolis, Oyo State, Nigeria. Specifically, the study identified solid waste disposal habits of residents, frequency of clearing the dumpsters, accessibility of waste dumpsters to people determines the waste disposal pattern of people; and analyze the willingness of people in Ibadan to pay for improved service. Solid waste management has been part of human activities right from time. Efforts by Oyo State Government are noticed in the collection of waste dropped on the median. Waste generation is an unavoidable product of man activities, however, sustainable management of such waste is a challenge faced in many countries today. Nigeria, a developing country in Africa, has been in a difficult situation of how to efficiently manage the municipal solid waste its growing population generates. Many states in the country lack adequate plans and infrastructure required for efficient and sustainable management of municipal solid waste. For Ibadan, the largest city in Nigeria, the problem is further compounded by its rather large and still increasing population. In this research, Ibadan metropolis is taken as a case study; the rate of solid waste handling in households as regards solid waste management from household collection to final disposal are focused upon. The study found out that $45.6 \%$ drop their refuse in the dumpsters as $18.8 \%$ burns their refuse, $17.7 \%$ of the respondents drops their waste on the median, $12 \%$ in the drainage while $6 \%$ opts to drop their waste in the streams.
\end{abstract}

On the effectiveness of the Private operators collecting waste from the respondents, the study found out that $7.6 \%$ effective, $37.5 \%$ of the respondents says the operators waste collection is poor, $7 \%$ says it is abysmal while $43.5 \%$ said it is not applicable to them because they do not have storage containers in their houses and as a result did not subscribe to their service. Many countries, particularly the developed ones, have employed options in the waste management hierarchy for sustainable management of their municipal solid waste and the blend of options employed is usually highly dependent on local factors. Following the waste management hierarchy, possible options for sustainable municipal solid waste management in Ibadan are discussed. It is concluded that waste reduction, reuse, and recycling are potential management options for the state. Landfilling will remain an important option for final disposal but reliance on this method could be significantly reduced if management options are exploited to the maximum in a sustainable solid waste management structure in Ibadan metropolis.

\section{Introduction}

Most human activities naturally results in the generation of waste. Waste generation is unavoidable in our day to day activities, which calls for waste generated to be managed. Rapid population growth makes waste management more challenging, more people in an area would imply higher level of waste generation. Poorly managed waste are seen as environmental hazards, the inabilities of societies to manage waste generated effectively play a great role in increasing the present environmental pressures (Alam et al., 2007). The challenge gotten from the generation of waste of waste is not just coping with the volume produced, but with the ability to design how to effectively and efficiently manage the waste in a sustainable manner. Ali (1999), noted that waste should be 
disposed of in a safe way which takes into cognizance the health of environment and that of the public at present, while ensuring non-detrimental effects on generations to come.

Anthropogenic activities have almost imposed huge threats to the environment. Waste is the most evident product of human activities. According to UNEP (2009), daily global generation of municipal solid waste in 2006 was reported as 1.3 billion tonnes per year but has been projected to increase to 2.02 billion tonnes by 2025 . It has been observed that there is scarcely a city or community that does not generate waste. The rapid acceleration of waste generated has exceeded the earth's carrying capacity by $30 \%$ in serving the pollution intensity (odum and Odum, 2006). One basic challenge in a community is that unwanted materials generated by the people are not adequately disposed. These unwanted materials are termed 'Waste'.

The World Health Organization (2008) defines waste as "something, which the owner no longer wants at a given time and space and which has no current or perceived market value". According to EPA (2007) waste could be in a liquid, gaseous or solid form and may constitute both biodegradable and non-biodegradable materials. The rapid increase of waste management has made the environment to undergo degradation as reported in various parts of the world, particularly id under-developed and most developed countries (Rahji and Oloruntoba, 2009; Ngoc and Schnitzer, 2009).

According to Oteng- Ababio (2011), most developed countries actively pursue efficiency in solid waste management (SWM), however the same cannot be said of the less developed counterparts, where inadequate access to funds, weak institutional framework, little staff encouragement, lack of access to appropriate technology, unending change in consumption trend continues to hinder the achievement of sustainability in the sector.

Therefore, this calls for an urgent need to assess the waste management system. In less developed countries like Nigeria, proper waste disposal has become a serious concern as many areas are developing without proper planning, inadequate governance, resource constraints and less attention are given to provision of proper refuse dumps. As a result of the inadequate planning, man has carelessly polluted the environment in a bid to dispose waste materials appropriately (Ololade et al., 2009). Sustainable development has become the target of modern society where economic progress works in hand with environmental preservation and conservation. Different technological approaches has been introduced to prevent the environment from degrading. Proper waste management has become more crucial in urban areas where the dense population has resulted in rapid waste generation.

\section{Objectives of the Study}

The aim of the study will be achieved through the following objectives:

1. To identify the solid waste disposal habits of residents at Ibadan metropolis, Oyo State.

2. To determine the frequency of clearing the dumpsters around the communities in Ibadan.

3. To determine the accessibility of waste dumpsters to people.

4. To analyze the willingness of people in Ibadan metropolis to pay for improved solid waste management in Ibadan Metropolis.

\section{Limitations of the Study}

This study is basically concerned with the social context of waste disposal pattern of residents in Ibadan metropolis. There are illegal waste disposal activities been done across the 11 LGAs in Ibadan metropolis. However due to time constraints, the study has limited itself to just 2 LGAs. As is usual in Household surveys, a few problems were encountered during the actual data collection 
process. In a few cases, individual households were unwilling to respond to certain questions. Depending on the type of missing data, those households had to be replaced on a random basis with households from the same ward. There was difficulty in communication due to language barrier, but it was solved with the aid of a research assistant. We are still confident that the data quality is high, as the questionnaire was carefully designed and the survey was well prepared and implemented.

\section{Materials and Methods}

Ibadan is the capital and most populous city of Oyo State, Nigeria. With a population of over 3 million, it is the third most populous city in Nigeria after Lagos and Kano; it is the country's largest city by geographical area. At the time of Nigeria's independence in 1960, Ibadan was the largest and most populous city in the country, and the second most populous in Africa after Cairo.

Ibadan is located in south-western Nigeria, $128 \mathrm{~km}$ inland northeast of Lagos and $530 \mathrm{~km}$ southwest of Abuja, the federal capital, and is a prominent transit point between the coastal region and the areas in the hinterland of the country.

\subsection{Source of Data and Sampling Procedure}

The study was carried out in Ibadan North and Oluyole LGAs respectively. Ibadan North is made up of 13 wards while Oluyole has 10 wards. Data were collected with the use of structured questionnaires, observations and Key Informant Interview. A stratified sampling technique was used to select three wards from each LGA to represent different classes of people in the study area. From each stratum a representative sample of 64 households were randomly selected to give a sample size of 384 households.

\subsection{Method of Data Analysis}

The Statistical Package for the Social Science (SPSS) will be used to analyze the obtained data. This includes the use of descriptive statistics (frequencies, percentages, charts) and inferential statistics (chi-square).A confidence level of $95 \%$ was used and p-values $\leq 0.05$ considered statistically significant. The descriptive statistics will give a clear account or representation of what is or what the immediate group of data will show while the inferential statistics will be used to derive a conclusion that extend beyond the immediate data alone; i.e. it enables the use of the sample data to make generalizations about the population from which the samples were drawn.

\section{Result and Discussion}

Table 1, the results of the study shows that of the 384 people interviewed, $49.7 \%$ were male and 50.3 female. As shown on table 4.1, the number of children given birth to by respondents shows that $28.4 \%$ had one child, $24.5 \%$ has two children, $10.2 \%$ has three children, $2.9 \%$ has four children, $1.3 \%$ has five children, $0.8 \%$ has five children and above while $32.0 \%$ of the respondents has no child yet. The age categorization of the people shows that $13.3 \%$ belong to $18-23 \mathrm{yrs}, 32.3 \%$ belong to $24-29 y r s, 32.3 \%$ belong to $30-35 y r s, 13.5 \%$ belongs to $36-49 y$ rs and $8.6 \%$ belongs to 50 55yrs. Further analysis shows that $35.9 \%$ were Yoruba, $18.2 \%$ Hausa/Fulani, 38.8\% Igbo were the majority of the respondents and $7 \%$ from other tribes. The survey revealed that $28.6 \%$ were single, $69.5 \%$ which represents more than average of the sampled respondent were married and a meager $1.8 \%$ of the respondents are divorced. 
Table 1

\begin{tabular}{|c|c|c|}
\hline Variables & \multicolumn{2}{|c|}{ Respondents } \\
\hline Gender & Frequency & Percent \\
\hline Male & 191 & 49.7 \\
\hline Female & 193 & 50.3 \\
\hline Total & 384 & 100.0 \\
\hline Number of children & Frequency & Percent \\
\hline One & 109 & 28.4 \\
\hline Two & 94 & 24.5 \\
\hline Three & 39 & 10.2 \\
\hline Four & 11 & 2.9 \\
\hline Five & 5 & 1.3 \\
\hline Others & 3 & .8 \\
\hline Total & 261 & 68.0 \\
\hline Missing System & 123 & 32.0 \\
\hline Total & 384 & 100.0 \\
\hline Age of Respondents & Frequency & Percent \\
\hline $18-23$ & 51 & 13.3 \\
\hline $24-29$ & 124 & 32.3 \\
\hline $30-35$ & 124 & 32.3 \\
\hline $36-49$ & 52 & 13.5 \\
\hline $50-55$ & 33 & 8.6 \\
\hline Total & 384 & 100.0 \\
\hline Ethnicity & Frequency & Percent \\
\hline Yoruba & 138 & 35.9 \\
\hline Hausa/Fulani & 70 & 18.2 \\
\hline Igbo & 149 & 38.8 \\
\hline Others & 27 & 7.0 \\
\hline Total & 384 & 100.0 \\
\hline Marital Status & Frequency & Percent \\
\hline Single & 110 & 28.6 \\
\hline Married & 267 & 69.5 \\
\hline Divorced & 7 & 1.8 \\
\hline Total & 384 & 100.0 \\
\hline
\end{tabular}


Table 2 shows that reuse of items is prominent in all the households that was sampled. The degree to which this is practiced varies from house to another, as such that at least one item made out of plastics such as water bottles, plates are reused in most of the house (Field survey, 2018) .Other items that are reused include textiles that are reused in the form of old clothing, these are given out to the less privileged, used as dusters or foot mats. Newspapers serve as art materials for school children, Nylons are reused to pack materials at different households. It was observed that the reused of different materials are tied mostly with economic benefits that maybe derived and it is sometimes born out of convenience

Table 2 represents the Overall distribution of disposal patterns of residents

\begin{tabular}{|c|r|r|}
\hline Variables & \multicolumn{2}{|c|}{ Respondents } \\
\hline $\begin{array}{c}\text { Type of Solid waste } \\
\text { generated in Household }\end{array}$ & Frequency & Percent \\
\hline Kitchen waste & 188 & 49.0 \\
\hline Paper & 104 & 27.1 \\
\hline Plastic & 53 & 13.8 \\
\hline Woods & 2 & .5 \\
\hline Nylons & 37 & 9.6 \\
\hline Total & 384 & 100.0 \\
\hline
\end{tabular}

The results on figure 1 shows the roles that storage container plays in the final disposal of waste, the study investigated the acquisition of storage containers through asking respondents to describe the means by which theirs was acquired. Of 384 respondents surveyed, $20 \%$ bought the storage container, $28 \%$ said it was provided by landlord while $52 \%$ did not have any storage container. From the study, it shows that onsite storage is a major problem. This shows that onsite storage is of primary importance because of public health concerns (Uchegbu, 2002).

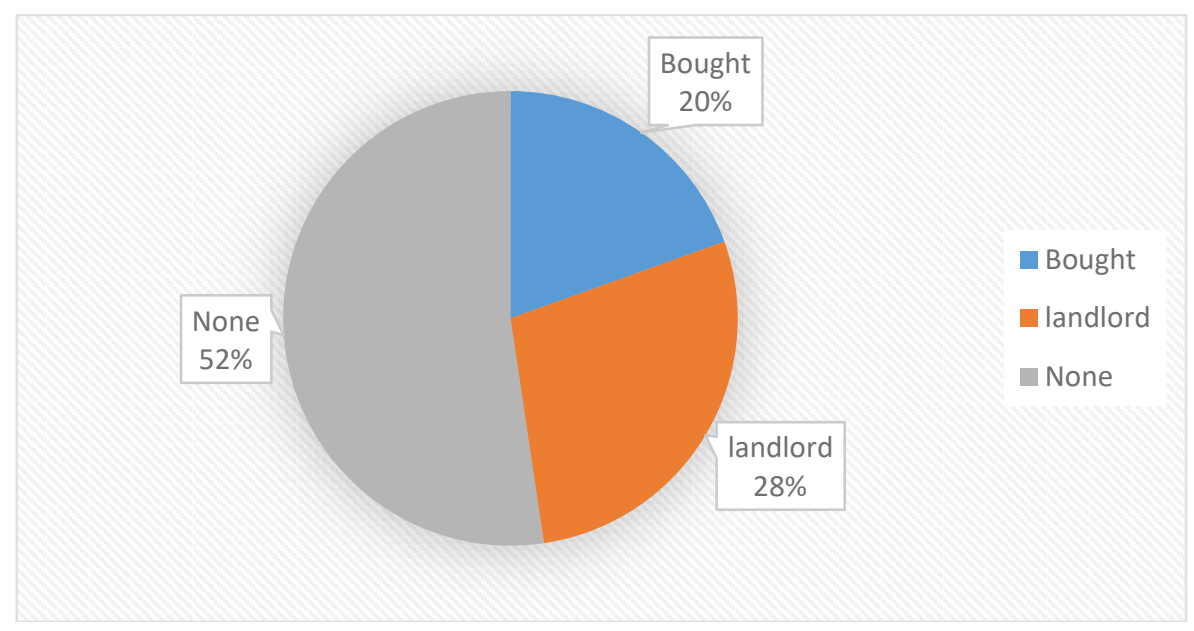

Figure 1 Distributions of respondents' means of acquiring a storage container

This shows different methods by which waste is been disposed by various households. The results in figure 2 shows that most of the respondents are involved in disposing their waste in dumpsters $(45.6 \%)$ as $18.8 \%$ burns their refuse, $17.7 \%$ of the respondents drops their waste on the median, $12 \%$ in the drainage while $6 \%$ opts to drop their waste in the streams. 
Majority of people are still disposing their waste in the drainage, streams and still burning their refuse which disfigures and pollutes our environment thereby contributing to the depletion of the ozone layer. There is an ongoing sensitization activity across the state to ensure that people buy a storage container to reduce the amount of waste container that goes into the landfills. Although it was tried in the past to subsidize bins and give nylons for free but the program came to an abrupt end.

This is consistent with the findings of Adewole, (2009) who identified unhealthy waste disposal habits of the residents, continual increase in the state's population, corrupt practices and lack of proper role definition among related agencies as some of the problems encountered in the management of solid waste in the city of Lagos. The interviews and observation in this study shows that the bins are being sold and given the financial constraints that maybe involved, a practical starting point in Ibadan would be to provide bins to each household at a subsidized rate. This also shows that many urban cities and towns do not benefit from any organized waste management services and therefore wastes are unattended to, buried, burnt or disposed indiscriminately (Ndinwa et al., 2012)

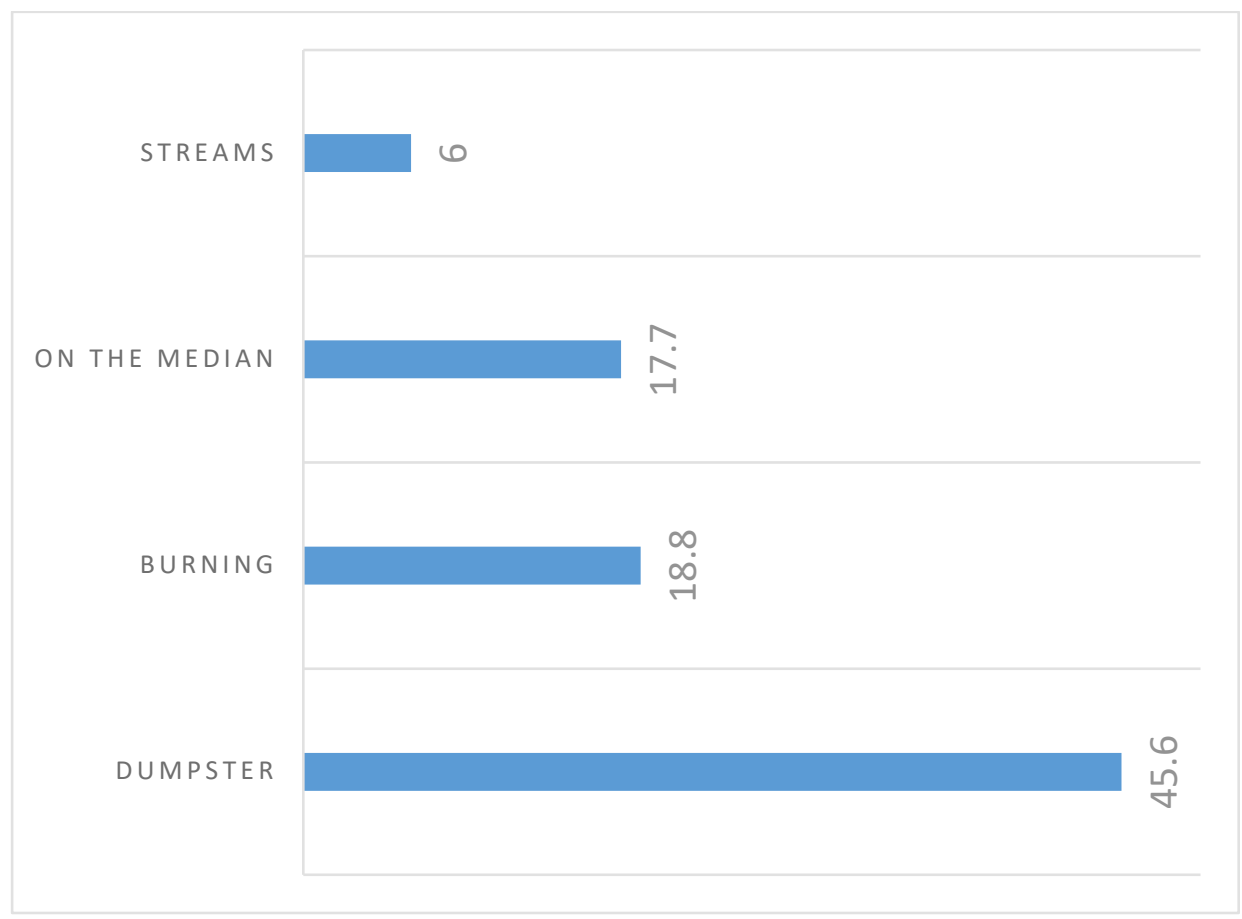

Figure 2 showing Respondents distribution pattern of waste disposal

To assess whether residents will be willing to pay for improved waste management service, the respondents were asked if they were satisfied with the operations of the waste collectors. $30.5 \%$ of the respondents responded 'yes' while $69.5 \%$ responded 'no'. In trying to know whether they would be willing to pay for improved service, $21.1 \%$ responded "yes and $78.9 \%$ 'no'. When probed further they believed that there is no justification for the amount of money that they are collecting at the moment as the rate been charged at the moment is dependent on the type of building and residential area been serviced and not on the amount of waste been generated. The respondents also noted that the operators litter their street after packing they litter the street as a result of overfilled vehicles and that the bins are handled carelessly.

It is often seen as though the waste collectors are not working but most times people do not pay for the services that is been rendered to them by this private companies. Sometimes 50 out of 500 people in a particular area pays the charged fee monthly and we have also seen a situation whereby everyone in an area owes about 6 months fee and they still want the operators to come and pack their refuse. 
Table 3 Distribution of Respondents' Satisfactory Level of Services Rendered by Operator

\begin{tabular}{|c|c|c|}
\hline Variables & \multicolumn{2}{|c|}{ Respondents } \\
\hline $\begin{array}{c}\text { Are you satisfied with the } \\
\text { services of the collector, if } \\
\text { yes skip }\end{array}$ & Frequency & Percent \\
\hline Yes & 117 & 30.5 \\
\hline No & 267 & 69.5 \\
\hline Total & 384 & 100.0 \\
\hline \multicolumn{2}{|c|}{ Prequency } \\
\hline $\begin{array}{c}\text { if No, will you be willing } \\
\text { to pay for improved service }\end{array}$ & 24 & 9 \\
\hline Yes & 243 & 91 \\
\hline No & 267 & 100.0 \\
\hline Total & & \\
\hline
\end{tabular}

Out of 384 respondents, $72.7 \%$ believe it is the role of the government to provide a safe environment for its citizens by providing dumpsters for the citizens as some people are been paid for the work while $27.3 \%$ said it is a good idea. The willingness to pay for is important for delivery of every social service including waste solid waste collection.

We have issues paying our private service operators as many people been serviced by them are not paying their fees on time which has left us short changed and unable to pay our operators. This has also made us to be unable to attract new personnel as others are been owed.

The study also revealed that the OYWMA has been confronted with logistics problem, inadequate personnel, and lack of incentives to attract new personnel.

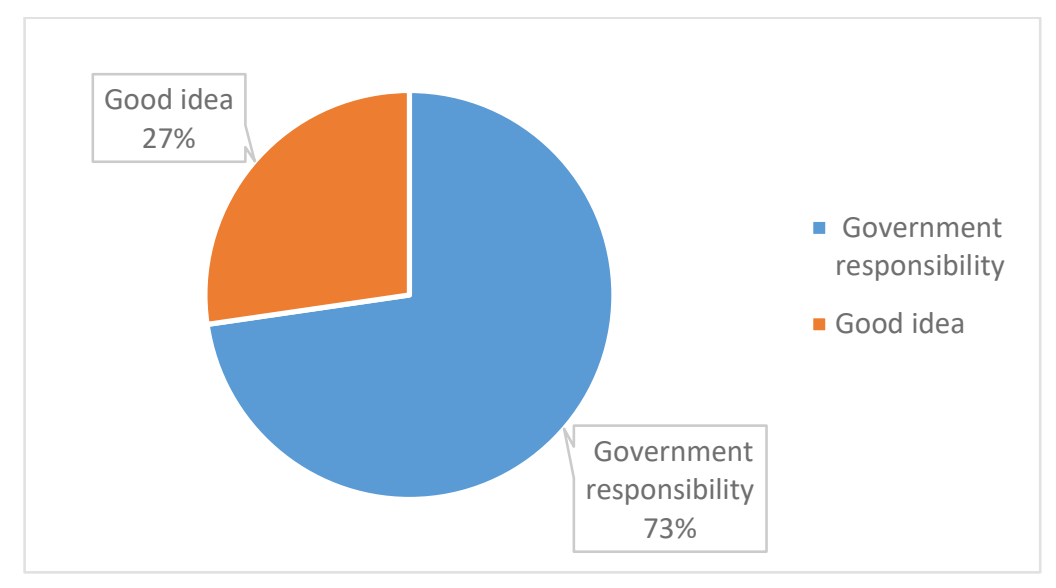

Figure 3

\section{Conclusion}

The results of the study reveals that majority of the respondents believe that for us to have an adequate and effective waste management system in Ibadan the government needs to do its own part which starts with providing a centralized dumpsters for people to dispose their waste effectively. 
The interviews and observation in this study show that waste is not segregated by households in Ibadan; yet introducing waste separation would be important to a successful implementation of other waste management options asides from the current one been used. OYWMA could make efforts to provide green and red bins to all households for storage of waste separately. Presently, the current criterion for provision of bins is by purchasing it from private individuals.

\section{Recommendations}

1. Provision of dustbins to the community members by the OYWMA which will help in the proper management of waste at household level and community.

2. Regular inspections of the household should be done by the Public Health Officers to ensure compliance to sanitation norms and regulations. It is recommended that homes should be visited at least once a week.

3. Community members have been noticed not to sort their waste because they do not understand the dynamics involved and are not conscious of the importance. Training should be organized to bridge the knowledge gap on this.

4. Incentives should be given to community members that sort their waste into recyclables like recycle points, Pearl recycling and lots more of started. It gives something back to the community members for taking the effort to sort their waste.

5. There is the need for OYWMA agency to recruit more workers and more sustainable vehicles needs to be used instead of the usual old trucks been deployed at the moment.

6. The government should provide a level playing grounds for private sectors to thrive in the waste management business as it can create lots of employment opportunities.

\section{Conflict of Interest}

The author declares that there is no conflict of interest

\section{Acknowledgement}

The utmost appreciation goes to God almighty for the success of this work. My heartfelt appreciation goes to everyone that contributed to the success of this work. I am glad to express my gratitude to Ugue Oluwaseyi and Gbadegesin Tosin. Special thanks to Dr. Temidayo Fawole for her support during the period of this research.

\section{References}

[1] Adewole, T. 2009. Waste Management towards Sustainable Development in Nigeria: A Case Study of Lagos State'. International Non-Governmental Organisation Journal, Vol. 4No.4, 173

[2] Alam, R., Chowdhury, M., Hassan, G., Karanjit, B., \& Shrestha, L. 2007. Generation, Storage, Collection and Transportation of Municipal Solid Waste- A Case Study in the City of Kathmandu, Capital of Nepal. Waste Management, 28(2008), 1088- 1097.

[3] Ali, M., Cotton A., \& Westlake, K. 1999. Solid Waste Disposal for Low-Income Countries. Leicestershire: Water, Engineering and Development Centre.

[4] Environmental Protection Agency EPA 2008. Classification of Wastes Information Bullet in EPA Publication 448: Environmental Data Base Management Team, Australia available at http://www.esdatnet. 
[5] Ndinwa et al ChuksChukwukaGabriel, Akpafun, 2012. Improvising Municipal Waste Disposal through Integrated Waste Management: The Southern Nigerian Experience Journal of Environmental Sciences and Resource Management Volume 4, No.34 p. 1

[6] Ngoc, U.N. and Schnitzer, H. 2009.Sustainable solutions for solid waste management in Southeast Asians Countries. Waste Management 29, pp. 1982-1995

[7] Odum, H.T. \& Odum, E.C. 2006.The prosperous way down. Energy 31, pp. 21-32.

[8] Ololade, I.A., Adewunmi, A., Ologundudu, A., and Adeleye, A.2009. Effects of Household Wastes on Surface and Underground Waters International Journal of Physical Sciences Vol. 4 No.1, p. 22

[9] Oteng- Ababio, M. 2011. Governance crisis or Attitudinal Challenges? Generation, Collection, Storage and Transportation of Solid Waste in Ghana. In S. Kumar (Ed.), Integrated Solid Waste Management (Vol. I). Rijeka: Intech.

[10] Rahji, M.A.Y., \& Oloruntoba, E.O. 2009.Determinants of households' willingness-topay for private solid waste management services in Ibadan, Nigeria. Waste Management and Research May 2009, 1-6.

[11] Uchegbu, S. N. 2002.Environmental Management and Protection. SpotlitePublishers, Enugu, Nigeria. 64

[12] UNEP. 2005a. Solid Waste Management (Vol. I). United Nations Environment ProgrammeInternational Environmental Technology Centre.

[13] W.H.O 2008. Traditional and Current Environmental Risks to Human Health. Health security through healthy environment. First Interministerial conference on health and the environment. P.5 